Tarih Kültür ve Sanat Araştırmaları Dergisi

Revue des Recherches en Histoire Culture et Art

مجلة البحوث التاريخية و الثقافية و الفنية
Vol. 7, No. 3, September 2018

Copyright (C) Karabuk University

http://kutaksam.karabuk.edu.tr

\title{
DOI: 10.7596/taksad.v7i3.1732
}

Citation: Sivtseva-Maksimova, P. (2018). A Comprehensive Study of the Olonkho: Discussion and Perspectives. Journal of History Culture and Art Research, 7(3), 293-301. doi:http://dx.doi.org/10.7596/taksad.v7i3.1732

\section{A Comprehensive Study of the Olonkho: Discussion and Perspectives}

\author{
Praskovia Vasilyevna Sivtseva-Maksimova ${ }^{1}$
}

\begin{abstract}
There is an increasing interest on the creative features of the Yakut epic olonkho in current literature. The article gives special focus to acknowledged researches of distinguished scholars who studied the oral epic heritage of the Sakha people. An overview of these researchers' works and their methodology is achieved with the following goal - to single out rationalized scientific approaches in the process of typological systemization of the Yakut epic based on the structural analysis of the olonkho plots and images; to explain the substantiated ideas expressed in complex research monographs by I.V. Pukhov, N.V. Emelyanov, A.P. Reshetnikova, and D.T. Burtseva as a systematic in-depth text analysis of the oral traditional art. In these aspects, there is a range of specific foundations that form the olonkho; this is explained in the research works in the form of plot classification and a fixed systemization of the main images together with a complex typological study of the unity of two planes - the epic content plane and the oral expression plane. The main dogmas of the research completed by Yakut scholars is advocated through the prism of theoretical issues and fundamental problems reflected in the works by Aristotle, H.W.F. Hegel, A.N. Veselovsky, E.M. Meletinsky on the aesthetics and poetics of oral forms of language art. Research results expand the range of possibilities of holding a complex study of epic, which does not exclude the possibility for scientific discussions. Perspectives for a complex olonkho research are in the fact that these research works reveal the creative onsets of the ancient oral art texts in a polyphonic concordance and in equal amounts. This is the conventionality in expressing the reality in its pure form, the inner completeness of a unified expression of the idea; and the originality, all of which cannot simply be taught; the uniqueness, equal to universality; the initial natural address towards the listeners, which can be equaled to the creative foundations of olonkho as one of the examples of unique epic storytelling forms.
\end{abstract}

Keywords: Epic genre aesthetics, Olonkho by P. A. Oyunsky, Plot semantics, Structural analysis, Epic ritualism.

\footnotetext{
${ }^{1}$ North-Eastern Federal University, Yakutsk, Russia. E-mail: smpv50@mail.ru
} 


\section{Introduction}

Yakut epic poetry is quite objectively defined as an ancient form of oral traditional art called olonkho, the creative/storytelling features of which are based on the praising "the absolute past" using images that are "unreachable in terms of hierarchy for the storyteller and the listeners". This is truly the king of literary work of art, where the main character "become all that he could have become.... and could only be what he had become" (Poetics, 2008, p.311). The genre aesthetics of olonkho can be characterized by a special completeness in the imagery of the characters, where the secondary (non-existent) reality in relation to the author can be equaled to the creative imagination of the highest level. It is precisely this storytelling feature which attracted the attention of the Russian Geographical Society members who were taking part in expeditions (A.F. Middendorff, 1869; E.K. Pekarsky, 1959); the political exiles - I.A. Khudyakov (1969), V.L. Seroshevsky (1896) and others. Their written records of Yakut olonkho validate the importance of the preserved unique forms of oral art as those being an exceptional indicator of the ancient culture of the Sakha people.

In his article titled The Yakut Language (1979, pp.379-380), A.E. Kulakovsky (1877-1926), the establisher of Yakut literature, a folklorist, an ethnographer, purposely describes a real-life episode as an evening with an olonkhosut (olonkho teller), where the first and foremost role of this kind of art performance truly manifests itself: "People listen to the fairytale from the early evening and until the early morning sleep", i.e., 13-14 hours straight.

"... People listen to it breathlessly, immersing themselves into the plot and trying not to make a single sound. As a matter of fact, the Yakut people are generally apathic kind of people, with a cold temperament being born under the cold sky... Everyone would forget about their chores and troubles and drift away into the magic and wonderful world of the imaginary... Like a true poet, the storyteller himself got carried away more than anyone else: he even closed his eyes in order to escape the sinful earth with its modern problems and prose completely... He forgot about sleep, rest, and everything in the world... the storyteller transformed completely in the eyes of the listeners: ... this is some kind of supernatural beautiful creature, surrounded by a mystical halo... Imagination has no limits in fairytales: it surpasses even the imagination in Arabic fairytales from the 1001 nights fairytales".

However, these advantages become feeble compared to the language of the fairytales: the language is poetic, picturesque and rich with its courageous similes, comparisons which are truly loved by the Yakut people and the imagery as well as the vast scope of words typical exceptionally for fairytales and songs.

One of the earliest significant representations of poetics in Yakut epic is an essay written by P.A. Oyunsky (1893-1939) titled Yakut fairytale (olonkho), its plot and contents $(1927,1962)$. In this essay, the author purposefully subdivides the text into 47 independent parts/questions, which refer to the content and structure of the Yakut epic story, and gives a thorough description of not only the ethnographic uniqueness of the idea of olonkho but also points out frequent mistakes and inaccuracies in the representation of various epic images in "modern storytellers" olonkho interpretations. For instance, in the chapter devoted to "the settlement in the middle world", which describes specific functions of the horned and horse cattle patrons, their place in the hierarchy of the worlds is also specified (1962, p.133).

The scholar's essay was first published in 1927 in a collection of scientific papers of the Sakha Keskile Society, which gives ground to suppose that the problems described in a fundamental study of the epic by the bearer of the storytelling traditions that keep on living are contemporary problems. In the concluding part of his work, P.A. Oyunsky (1962, p.194) makes a reasonable conclusion that "the olonkho predetermined the worldview of the ancient Yakut people; it also encompasses and depicts the entire ancient period in the life of the Yakut people, their pre-history". 
Thus, in the early representations of the epic stories told by the bearers of this phenomenon, the uniqueness of the olonkho and olonkhosuts (olonkho tellers) is signified; at the same time, there are debatable instances connected with the genuine originality of the oral art form, which withholds ancient traditions serving as representations of the world and the beliefs of the Sakha people.

\section{Goals and Hypothesis}

The aim of the present research is to justify the necessity for an in-depth study of the olonkho structure and images through the prism of theoretical dogmas in aesthetics and poetics of language arts presented by Aristotle, G.W.F. Hegel, and A.N. Veselovsky and the fundamental studies of the epic genre of the peoples of Siberia carried out by E.M. Meletinsky.

The goal of the study is supported by the fact that in determining the creative value of a folklore work of art, the skill of performing and oral art piece is an integral part of content and genre parameters of ancient oral texts. In this respect, the olonkhosut or olonkho teller is regarded as highly knowledgeable bearer of traditional culture and not only as a talented storyteller but also as an aesthetic person, thinker similar to the ancient wise men and witnesses of the initial traditions. The traditional poetry in the olonkho images unfolds in such representations of the world and social life which are absolutely equivalent to the world art creative systemizations of plots and motifs. In this respect, the oral form of art in which these stories are presented is equal to the indicators of active dynamic changes of these representations based on the traditional aesthetics as a part of a general human culture.

\section{Methodological Framework}

The research is carried out within the framework of the chronology problem typology represented in the researches on the complex study of olonkho. The systematic and comparative point of views on specific fragments and materials presented in monographs by Yakut folklorists are based on singling out the traditional problems of the epic genre and their scientific novelty as well as the importance of carrying out a typological and structural analysis in the complex study of the Yakut olonkho texts.

\section{Results and Discussion}

The initial interest of the Russian Geographical society members in the Sakha epic during their expedition in the north and other individuals during their exile is connected with the unusual content and a large number of Yakut stories that were being told as well as with the unusual name for these stories - olonkho and this is what makes it unique. Middendorff (1869), Khudyakov (1969), Seroshevsky (1896), and Pekarsky (1959) define it as a fairytale; meanwhile they also specifically note that it is close to bylinas, epic songs, poems and epopees. The first "contradictory" versions of the texts are presented in the research by D.T. Burtsev (1998), devoted to the problems of defining the genre of olonkho. As one of his justifications, the researcher brings an example of an observation made I.A. Khudyakov (1969, p.336): "...Some time ago, during my student years, I thought it incredible for one traditional storyteller to know and be able to tell such a long fairytale comparable in length to the Iliad and Odyssey by heart and indicating such a great number of proper names, adding exquisite detail. Yakut storytellers tell such long stories with such incredible attention to detail using poetry and chants... Sometimes the Yakut people themselves are surprised by the length of the stories" (Burtsev, 1998, pp.4-5). Here it is worth mentioning that this abstract from the research carried out by the famous 19th century Russian folklorist is also quoted (before the research work by D.T. Burtsev) in the introduction of the monograph by N.V. Emelyanov titled Yakut olonkho plots (1980, pp.12-13). 
In research conducted by D.T. Burtsev $(1998$, p.7), the historiography of the debates around the definition of genre features of folklore epic are complemented by an indication to the illegitimacy in the description of location or the paths trotted by the bogatyr to search for the indications of specific geographic locations: "Geographical localization of olonkho is apparently illegitimate. The mythological Middle World in the Yakut epic... is represented... by the deadly mythological seas and other mythological loci".

The key concept of the research conducted by a modern-day olonkho researcher lies in the evidence of the Yakut epic tales importance as being an archaic form of art, to which the "method of 'concrete historism' is not fully applicable" (1998, p.7). Remarks made by D.T. Burtsev concerning the dogmas described by P.A. Oyunsky in his essay, are supplemented by a third significantly important observation. D.T. Burtsev completely disagrees with the interpretation of the name of the deity of fortune - Genghis Khan as an allusion to the historical figure of Ghenghis Khan. The scholar supports his critical comment with conclusions on this issue made by the following Yakut scholars in their research works: G.V. Ksenofontov (1937, p.474), N.V. Emelyanov (1962, p.89), N.K. Antonov (1971, p.121).

The essay by P.A. Oyunsky is of a great value. First of all, due to the fact that it is a research carried out by the bearer of living dynamic traditions of folklore storytelling. The storytelling aspect in the history of epic art is equaled to the main features of this genre in the research works written by E.M. Meletinsky. Interestingly, in his monograph titled "The origin of heroic epic" he supports his ideas by referring to P.A. Oyunsky and I.V. Pukhov and their research.

He particularly mentions the following characteristic features of this part of storytelling genres: "Apparently, rhythm-building is first of all achieved through the speech of the main characters (in olonkho, for instance, each character has "their own style and melody of speaking); it is also evident in the descriptive part of the plot which is a typical feature for heroic epic genre in contrast to fairytale genre". The monograph confirms further on in the text that among the oral forms of folklore art, epic folklore contains archaic features and in this respect it becomes "an exceptionally valuable" as a form of epic culture of the "Turkic peoples of Siberia not only in terms of researching the history of culture of the peoples mentioned earlier, but also in terms of looking into the origin and development of the heroic epic genre itself" (Meletinsky, 2004, pp.255-256).

We can only assume that the systemization of the creative features and the discussion of the spiritual value that this epic possesses represents an initial stage of working on the olonkho text written by P.A. Oyunsky in his essay titled Yakut fairytale (olonkho, its plot and content) (1927). First of all, his written text version of the olonkho Nyurgun Bootur, the Swift plays a significant role in the history of Sakha epic art studies. Secondly, the main ideas and conclusions made by this scholar, who was greatly knowledgeable in mythology, have been expanded in the research works by I.V. Pukhov, particularly in his fundamental studies of the structure and images of the Turkic-Mongolic peoples folklore art (2004) and in the afterward comments to the written olonkho text by P.A. Oyunsky (1975). His legacy is the most cherished research subject for I.V. Pukhov, who was a folklorist and an expert in literary studies. He wrote about the uniqueness of the poet and proved that Nyurgun Bootur, the Swift is a classical version of the text "of one of the best and most popular Yakut olonkho" recreated by the olonkho teller: "P.A. Oyunsky wrote his own version of olonkho about Nyurgun Bootur, the Swift (which he performed in front of the public)" and "this olonkho is completely composed following the traditions of the Yakut olonkhosuts (olonkho tellers); it is one of the variants of traditional olonkho and not a compilation of olonkho compiled by the author" (Pukhov, 2013, p.27).

The scholar further makes a very important remark about the time-period when P.A. Oyunsky wrote his version of olonkho about Nyurgun Bootur the Swift: 
"Apparently, he wrote it very quickly. It is uncertain when exactly he had started to work on his writing. The first song (there are nine songs in total) was finished and published in 1930; he indicated the date of finishing the written work at the end of the ninth song: August 31, 1932. Moscow. Generally, he wrote this olonkho for about two and a half years according to the calendar time. During the years of working on the olonkho, he did public service in Yakutsk, and postgraduate studies in Moscow. He was also actively involved in social, political and creative work. For these reasons, he had an insignificant amount of time to work on the written version of olonkho. The fact that he knew olonkho by heart (being and olonkho teller) helped him to write down what he had stored in his memory for a long time in a smaller time-period" (Pukhov, 2013, p.24).

I.V. Pukhov was fascinated by the creativity of the author of a classic olonkho text, a fact which is advocated in the preface to the Russian edition of the epic translated by Vladimir Derzhavin: "P.A. Oyunsky knew and was also interested in other forms of art apart for olonkho: he knew a large number of other Yakut folklore examples. Folklore played caused a great positive impact on his entire creative art and it was that one representation of the native land which he used for support and swept to the top of creative achievements" (Pukhov, 1975, p.419).

Our next remark: the plot and structure of the Yakut folklore text created by P.A. Oyunsky can be compared with the functional characteristics of oral art of the antiquity. In Poetics, Aristotle focuses special attention to a detailed analysis of tragedies. He singles out such compulsory elements of classical rhetoric as plotline (mythos), the attitude of the characters (ethe), speech (lexis), thought (dianoia), performance (opsis), and music (melos) (Aristotle, 2000, pp.31-33). In Aesthetics, Hegel proves that classic tragedies are the most genuine form of art, which unravels the origins of philosophical interpretation of life and society.

In the poetic structure of olonkho, the creative basics enumerated by Aristotle as classical elements can be traced in the description of the three-leveled world and the aiyy bogatyr's ancestry, which serve as the plotline of the story. Dynamic portraits of the characters are based on their actions which describes their attitude (ethe). Their extended monologues and dialogues represent classic forms of creative speech (lexis). The idea of olonkho (dianoia) is based on clearing the middle world of all evil (Aristotle called this catharsis); in the spectacular description of the bogatyr's deeds (opsis) and in the thorough description using special performance voice (melos) we can also see the presence of the obligatory details of classic oral art.

Being a poetic form of art devoted to the mythological time-period, it is initially aimed at praising the ideals in the form observing the world surroundings and time. In this respect, in Aesthetics by Hegel, art is proved to be an initial representation of the absolute; it is followed by religion and the most genuine representation is philosophy: "... The ancient Greeks considered art as the supreme form of creativity, in which the people depicted their representations of gods and reached the truth. Poets and artists became the creators of the Greek gods, i.e., artists gave the nation a specific representation about actions, life and the impact of the deities. There, artists presented the people with a particular representation of religious content" (Hegel, 1968, p.110).

Yakut epic can also be characterized as having such parameters as typology of deity images and a specific compositional gradation of the plotline. The poetic form of olonkho can certainly serve as proof of being "an archaic type of poetic speech", which had been indicated by scholars as a form of epic storytelling "at the initial stage of the Turkic poetry development" (Titivaldi, 2002, p.78). A.E. Kulakovsky (1979, p.452) suggested that "alliteration of the Yakut poems is much more advanced due to the fact that it contains not only one vowel or consonant but an entire syllable and extends for not just two or three lines but ten to twenty lines".

Fundamental research carried out by N. V. Emelyanov is devoted to a complex systemization of the Yakut epic plots; his research has been largely acknowledged by the folklore researchers specializing in epic 
studies in Russian and the Commonwealth of Independent States. His monographs present a scientific classification of the olonkho plot abstracts. He subdivides the epic texts into three main groups: olonkho about the inhabitance of the Middle World, olonkho about the first ancestors of the urankhai Sakha tribe, and olonkho about the defenders of the aiyy tribe. Particularly valuable remarks were made by N.V. Emelyanov (1980) in his research, in which he indicates the sources of all the written olonkho records (a total of 75 plots); he provides their full scientific description and glossaries, which assist the reader in an indepth study of the epic text features. In the introduction, he notes that "olonkho was preserved and passed on in an oral form in the course of centuries from the ancient times to the present day". He also notes that the topic of his research "was suggested by G.U. Ergis (1909-1969)" (Emelyanov, 1980, p.14). This provides a strong evidence to the fact that the main concerns of Yakut folklorists are interconnected; they believe that starting from A.E. Kulakovsky and P.A. Oyunsky, olonkho should be the main subject of a thorough study. In his subsequent researches, N.V. Emelyanov $(1983,2000)$ singles out a typology and structure principles of olonkho created earlier in the ancient period; he also describes the poetics of the images in the context of the olonkho plot studies, in which olonko texts tell about the first ancestors of the tribe and for the very first time, a separate classification of the main type of olonkho is made, devoted to the olonkho about the defenders of the tribe and containing a description of the genre evolution in terms of the special features of these ancient epic texts.

An equally important scientific research was devoted to a systemization of the syncretic structure of the epic texts in a monograph by A. P. Reshetnikova titled The scope of plot motifs and the melody of olonkho in the context of ethnography (2005).

The fundamental study represents a structural analysis of the Yakut olonkho texts in a comparison with the ritual culture materials, which confirm the ethnographic origin of the beliefs and mythological worldview of the Sakha people. In this respect, the scholar rationalizes the importance of plot motifs and folklore plot studies in terms of their general cultural value; the author of the monograph also provides justifications for the compared facts, which perform special functions of narrative/communicative phenomena in olonkho in the process of literary systemization.

It is also worth confirming here the value of the points of view represented in the A.P. Reshetnikova's research: the scholar determined the principles of historical poetics. A.N. Veselovsky suggests the following perspective goals of studying the national (ethnographic) origins of poetry: "a genetic explanation of poetry as a psychological act predetermined by the art forms known to humanity, and consecutively stored and preserved in the course of history". The scholar further stresses the fact that poetry being a live process, upgrades itself "in a constant interchange of offer and demand along with personal art and the reaction of the public"; the characteristics and literary features are formed in the course of this interchange (Veselovsky, 2006, p.83).

A structural analysis of the Yakut olonkho texts and the Evenki nimngakans (epic tales) is regarded by A. P. Reshetnikova in different research aspects, in which the syncretic nature of the early form of epic genre manifest themselves.

First of all, this serves as a confirmation of the musical basis of olonkho as an oral form non-material heritage. Based on the fact that different forms of folklore represent "a musical system" by their nature, the typology of styles A (dzhiereti), B (kuturu), C (degereng) are equaled to the main code of the chant part of the epic performance. "Stability, typical for $A$ and $B$ styles, which are used to depict the sacred characters in the mythical Upper and Lower worlds, are similar to conventionality of words, which is gives expresses a certain notion on a permanent basis" (Reshetnikova, 2005, p.59). The conclusions made by the scholar are support with unique source materials: note records made by Middendorff, L. V. Seroshevsky, V. I. Jochelson (Reshetnikova, 2005, p.7-10); classifications of olonkho songs created by F. G. Kornilova, G. M. Krivoshapko, 
and S.A. Kondratyeva. These also include works of E.A. Alekseev, a Yakut folklore music researcher; records of famous olonkhosuts U.G. Nokhsorov and N.P. Burnashova based on numerous examples of Yakut olonkho (Reshetnikova, 2005, pp.10-51). In another monograph, A. P. Reshetnikova analyzes the performance music score of the olonkhosut G. G. Kolesov (Reshetnikova, 2016, pp.255-263).

The olonkho plot study is represented in the form of a dynamic comparisons of the epic and traditional rituals based on motifs as well as in the systemized form representing the structure of each separate text. The amount of analysis data should be specified here: it comprises of 87 olonkho texts which can be compared to a considerable amount of ritual and ceremonial descriptions.

Meanwhile "their comparison with ethnographic data" reveals a unique creative function of the epic ceremonies in the olonkho plots: "Epic texts do not simply reflect the objective reality in the form of traditional rituals, but also complements this semiotic system using accessible tools" and based on this confirms "the implied subcontext of traditional ceremonials" (Reshetnikova, 2005, p.77). The monograph gives a thorough description of not only the significant differences but also points out interesting typological similarities, analogies/repetitions in full detail, providing over 40 important olonkho and nimngakan motifs (Reshetnikova, 2005, pp.68-222, 277-339).

In the monograph, A.P. Reshetnikova not only analyzes the creative features of the Evenki epic compared to that of olonkho (being the first scholar to conduct such research), but also systemizes the issues of a typological study of totemism relicts in the Turkic and northern peoples culture in comparison with the Slavic and European folklore images. Having analyzed and systemized a large scope of ethnographic and folklore materials and sources, the scholar manages to supplement the conclusions and dogmas put forward in the studies by P. A. Oyunsky, I. V. Pukhov, and N. V. Emelyanov.

The novelty of these studies is achieved through a complex in-depth analysis and this is how we regard it. The importance of Yakut olonkho in the comparative study of Turkic-Mongolic peoples epic and in the scientific commentary of the system of olonkho characters is justified; olonkho is considered to be a classic type of storytelling (Pukhov, 1975, 2004, 2013). The scientific classification of olonkho plots contains a large scope of content, the deepness of the idea behind the ancient Yakut epic (Emelyanov, 1980, 1983, 2000). The uniqueness of olonkho as a genre is characterized by the ability it possesses to auto-control the folklore text in the form of a unique creative process (Burtsev, 1998). There is profound evidence of new trends in the scientific study of the Yakut epic creative features in the form of structural analysis; these researches include: the study of musical structure, scope of plots, function of the motifs, olonkho images, all of which explain the features of this form of heritage of the Yakut oral art as a live dynamic creative system (Reshetnikova, 2005, 2016).

\section{Conclusion}

In general, in-depth study the folklore and at the same time its systemization in the form of a unified structure represents a complex research material, which requires special research skills on the part of the researcher. In this sense, the study of olonkho is based on debates such as the searches for a new (and more correct) distinction of the certain epic features or storytelling art as a form of live traditions. All this makes olonkho incredibly valuable study material being a dogma of art, which also represents the origins of literature from the methodological point of view; its poetics in the creative process is defined as the "eternally live archaics" (M. M. Bakhtin). The perspectives for a complex olonkho study are in the fact that these works are explained in a pophonic concordance and they are equal in terms of their oral ancient creative text onsets. This conventionality in the expression of the objective reality, the inner completeness of expressing an idea, and originality are all features that cannot be taught. Uniqueness is equal to generalization and the initial address towards the listeners. 
All "the laws of creativity" can be defined by their general features and uniqueness in the epic olonkho images, owing to which, the text achieves originality and singularity in their images and plots, which specifically serves as a guarantee of being recognized as a form of independent spiritual culture. A complex study of the olonkho texts allows justifying the evolutionary parameters in the plots and motifs in the sense that old age is somehow reflected in the perspective, due to the fact the epic and mythological bases of olonkho have always represented the creative reality and existed in the realistic facts in the history of traditional way of life.

\section{References}

Antonov, N. K. (1971). Materials on the historical vocabulary of the Yakut language. Yakutsk.

Aristotle (2000). Poetics. Rhetorics. St. Petersburg: Azbuka Press.

Burtsev, D. T. (1998). The Yakut epic olonkho as a genre. Novosibirsk: Nauka Press.

Emelyanov, N. V. (1962). Yakut proverbs and sayings. Yakutsk.

Emelyanov, N. V. (1980). Yakut olonkho plots. Moscow: Nauka Press.

Emelyanov, N. V. (1983). Early olonkho plots. Moscow: Nauka Press.

Emelyanov, N. V. (2000). Olonkho plots about the defenders of the tribe. Novosibirsk: Nauka Press.

Hegel, G. W. F. (1968). Aesthetics. Vol. 1, Moscow: Iskusstvo Press.

Khudyakov, I. A. (1969). Brief description of the Verkhoyanskiy region. Leningrad: Nauka Press.

Ksenofontov, G. V. (1937). Urankhai sakhalar. Notes on the ancient history of the Yakut people. Irkutsk: Vostochno-Sibirskoye knizhnoye izdatelstvo.

Kulakovsky, A. E. (1979). Scientific works. Yakutsk.

Meletinsky, E. M. (2004). The origin of heroic epic. Early forms and archaic artifacts. Moscow: Vostochnaya literatura of the RAS.

Middendorff, A. (1869). A journey to the north-eastern Siberia. Part 2. The north and the south of Siberia in the natural and historical context. St.-Petersburg: The publishing house of the Emperor's Academy of Science (RAS).

Oyunsky, P. A. (1927). Yakut fairytale (olonkho), its plot and content. A collection of works "Sakha keskile", Edition 1(4), Yakutsk, 98-139.

Oyunsky, P. A. (1962). Yakut fairytale (olonkho), its plot and content. A collection of scientific records, Vol. 7, Yakutsk, 128-194. 
Pekarskiy, E. K. (1959). Dictionary of the Yakut language. Moscow: Academy of Sciences of the USSR, Vol. 13, clmn. 3858.

Poetics (2008). Dictionary of contemporary terms and definitions. Ed. by N.D. Tamarchenko. Moscow: Kulagina Publishing.

Pukhov, I. V. (1975). Comments. Nyurgun Bootur, the Swift. Yakut heroic epic olonkho. Reproduced by Platon Oyunsky based on the myths and legends. Translated into the Russian language by Vladimir Derzhavin. Yakutsk, 411-422.

Pukhov, I. V. (2004). The heroic epic of the Altai-Sayan peoples and Yakut olonkho. Yakutsk.

Pukhov, I. V. (2013). Olonkho - an ancient epic of the Yakut people. Yakutsk: Saydam.

Reshetnikova, A. P. (2005). The scope of plot motifs and the melody of olonkho in the context of ethnography. Yakutsk: Bichick Press.

Reshetnikova, A. P. (2016). Olonkho uonna torut kultuura: sier-tuom, yrya-toyuk altyhyylara. Yakutsk: RIO media-holding.

Seroshevsky, V. L. (1896). The Yakuts. An ethnographic study experience. Vol. 1, St.-Petersburg.

Tilivaldi, Vlizhman (2002). Ancient Turkic poems. Almaty: Abai Kazakh National Pedagogical University

Veselovskiy, A. N. (2006). Historical poetics. Moscow: ROSSPEN Publishing. 